\title{
Conceptual Model of Knowledge Management and Social Media to Support Learning Process in Higher Education Institution
}

\author{
Tanty Oktavia ${ }^{* 1}$, Harco Leslie Hendric Spits Warnars ${ }^{2}$, Suroto Adi $^{3}$ \\ ${ }_{1,3}$ School of Information Systems, Bina Nusantara University \\ JI. K.H. Syahdan No. 9 Palmerah, Jakarta Barat - 11480, (021)-5345830 \\ 1,2 Doctor of Computer Science, Bina Nusantara University \\ Jl. Kebon Jeruk Raya No. 27, Kebon Jeruk, Jakarta Barat-11530 \\ *Corresponding author, e-mail: toktavia@binus.edu ${ }^{* 1}$, shendric@binus.edu ${ }^{2}$, sadi@binus.edu ${ }^{3}$
}

\begin{abstract}
Nowadays social media has tremendously transformed organizational business process of institution. Higher Education as a place with the majority generation $Y$, that advances to use technology should realize these situations. With this social media platform, institution may facilitate the knowledge transfer process, then to support collaborative learning from e-learning to social learning. Referring to this phenomenon, this research will design the integration of concepts of knowledge management and social media as a framework to identify the significant components and its relationship to support each other. In this research, we use a systematic literature review from journal and text book to construct this collaboration model. The outcome of this study is collaboration model of knowledge management and social media to support learning process in higher education institution.
\end{abstract}

Keywords: social media, e-learning higher education, knowledge management

Copyright $@ 2017$ Universitas Ahmad Dahlan. All rights reserved.

\section{Introduction}

Nowdays institution believe that with using believed that knowledge management systems can drive institution become efficiency, effectiveness, and competitiveness because it can support knowledge sharing among organizational member. The increased interest of knowledge management makes many organizations investigate and implement knowledge management framework for managing and utilizing intellectual asset in their organization, one of them is higher education.

Meanwhile, social media has enhanced the way how people interact with each other (1) because with social media there are numerous data can be obtained from source of information (2). Using social media, users can post everything (quote, link, image, video, etc.) and to comment and share with each other. Facebook, Twitter, Google+, Path and others as a part of social media have become very popular for young people. Those media can provide an easy way to access or exchange information between people. This is how people interact with others in Web 2.0 environment. Such effect is not only confined at the personal life, but also in social life. At the institution level, social media support people to interact, share information, and collaborate in all business processes. Furthermore, social media has eliminated barriers in connectivity, which has helped individuals keep contact with his/her friends (3).

According to this phenomenon, this research identifies what the major component of social media environment and knowledge management aspect which can support learning activity in higher education institution.

\section{Theoritical Background}

\subsection{E-Learning}

E-learning systems are known as multidisciplinary concept. Many researchers from any other fields, such as information systems, computer science, psychology, education, etc., have been describing e-learning concepts. Some have focused on technology, where others have 
studied only the human behavior factor like student and instructor satisfaction. E-learning system can use multimedia channel such as video, audio, text, graphic, image, etc to support teaching and learning experience (4). According to this capacity, learners can deeply explore their knowledge about a subject.

Since the objective of this study was to identify component of social media and knowledge management to enhance learning process, there are some frameworks of e-learning founded from study literature process. One of the famous applicable framework of e-learning according to Khan model, contains eight dimensions (5) Figure 1: Institutional, Technological, Interface, Evaluation, Management, Resource support, Ethical, and Pedagogical,

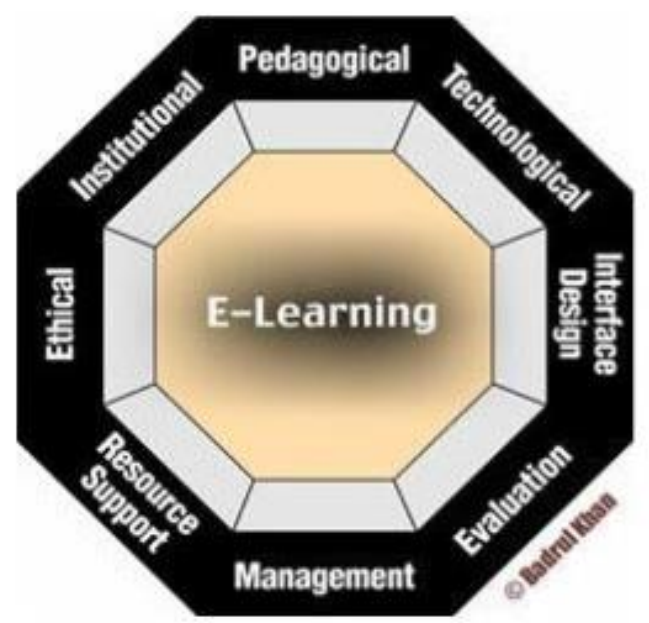

Figure 1. E-Learning Framework (5)

The structure of e-learning process is different with conventional learning. Conventional learning-based in a static system that be held in the classroom, but e-learning use dynamic system, which instructors and learners can specify when and where they want to continue the learning activity.

\subsection{Social Media}

The tremendous development of technology has changed how learner to solve the problem. Currently, there are a huge number of social media that can be used to explore many information that they need. With social media could be a tool to support learning process (6). Therefore, higher education institution must be prepared to embrace the opportunities and challenges using social media. The functionality and the usage of social media have spread into seven components, as described in honeycomb framework in Figure 2. This framework shows the seven building blocks of social media functionality which each part allows us to examine user experience and its impact for organizations (7).

The following are seven functional building blocks of social media, consist of (8):

1. The identity, this function represents learner to identify their profile in social media platform, such as age, gender, location, and all additional description that can describe about social media users.

2. Conservation functional block decribe the communication process in social media. The conversations which can be used in social media environment.

3. Sharing describe the function to that user can exchange, disseminate, and receive object (e.g. video, picture, sound, link, text, location, etc.)

4. Presence represents status users. It shows which user is accessible. In the reality, this happens through update status like "available" or "invisible". This block can increase interaction of people, which bridges the real and virtual. 
5. Relationships. This block describes the function which user can be connected to other users. Consequently, how users are interacted that often specify how and what of information exchange.

6. Reputation is the function to which users can identify the standing of someone, including themselves, in a social media setting. However, in social media, reputation refers not only to people but also their content.

7. Group functional block describe the extent to which users can form communities and subcommunities.

Social media platform in higher education institution gives a place or a learning space for learner who can interact with their connections as well as interact about learning process in their convenience space and time (9). This generation came from the last two decades of the 20th century (10).

In addition functionalities to the classroom learning process, the collaboration process in social media has an advantage to enriched teaching and learning, the development of learning skills, authentic learning, interactive learning groups, and student-centered pedagogy (11).

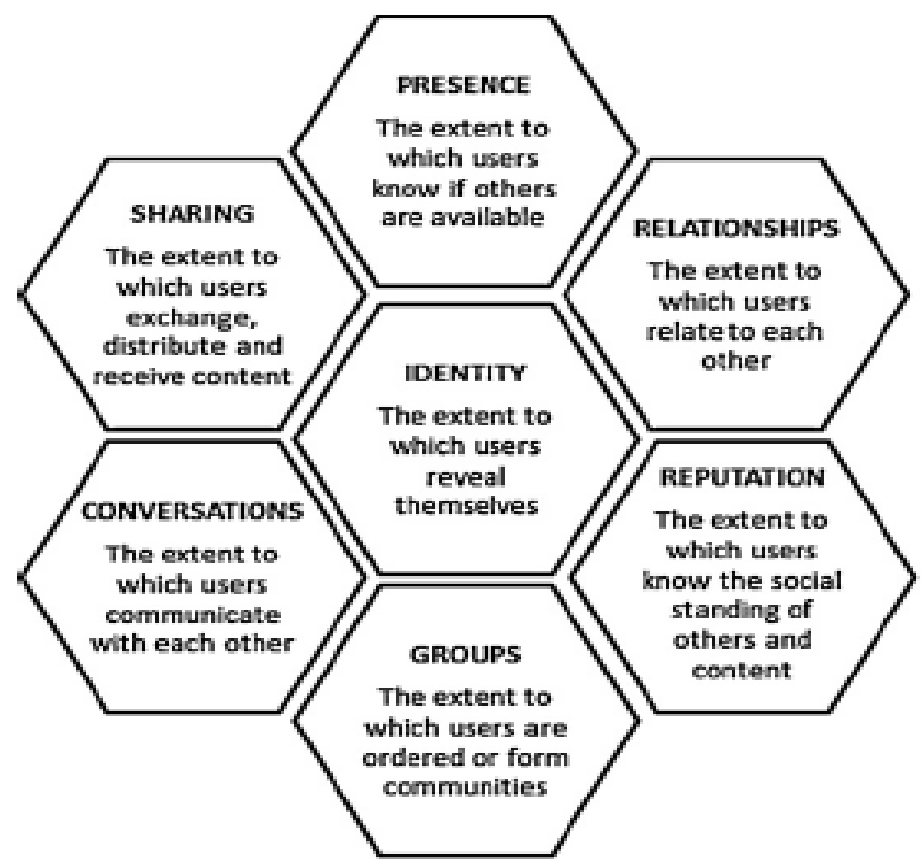

Figure 2. Social Media Functionality Framework (7)

\section{3. e-Learning}

The human dimension has 3 (three) implications, which are the subject of learning activities, human-based social network, and human-based social culture (12). When interaction has a direct impact to the learners' intellectual growth, it can be concluding the interaction meaningful to the learning process (13). The uses of social media can enhance learning process, complementing face to face session so the holistic learning experience can be achieved (14). When the learning environment need interaction with other people (classmates, experts, outside authority), it's a social learning concept (15). The types of social learning consist of dialog with industry, feedback, mentor, teacher, and coach; collaboration on the project, discussions with experts, professional network, or online community.

Human knowledge is built through interaction between explicit and tacit knowledge, so it is necessary to implement the social learning to eliminate any barrier in peer interaction to accelerate knowledge process optimization and to help learners obtain maximum learning efficiency (12). Moreover social learning environment, learning more interactive by dynamics minds to solve any kinds of problem (15). 


\subsection{Knowledge Management Systems}

Higher education creates knowledge during the learning processes. Knowledge is created to explicit knowledge in the form documents, video, procedures, etc at various levels (faculty, students, administration, academics, etc.). Each level creates knowledge as well as use knowledge. Capturing and building the institutional knowledge still available will ensure the longterm continuity in learning process. Despite this fact, there are a lot of approaches to knowledge management system have been implemented across organizations to fully realize its potential for increasing organization performance (9). For this study, we try to use the implementation of knowledge management system for higher education learning process.

\section{Methodology}

In order to identify the most significant factor to integrate social learning and knowledge management, this research consist of several steps:

1. First step was conducted by identify and analyze data about social media and knowledge management platform.

2. Second step we try to identify knowledge management part, e-learning framework, and social media framework from any kind literature, such as journal, book, and articles.

3. The last step, we integrate each component towards a collaboration knowledge management model and social media.

\section{Result and Discussion}

Many organizations have a perspective that e-learning system has a similar attributes as basic knowledge management processes and thus can be used as a tool for concept of knowledge management (16). Defining a suitable Knowledge management is the key element of Knowledge management implementation (17). In order to develop a suitable knowledge management framework for higher education, this study identified some of component of knowledge management that already implemented in organisations. After process reviews on literature from 2004 until 2015, there are consists of 8 (eight) component variables that have impact to implementation Knowledge Management, which are in Tabel 1:

Table 1. Compontent of Knowledge Mangement

\begin{tabular}{|c|c|c|}
\hline Components & Description & References \\
\hline Technology & IT infrastructure and technology utilization & $\begin{array}{l}(18)(19)(20)(21)(22) \\
(23)(24)(25)(26)(27)\end{array}$ \\
\hline Intellectual asset & Knowledge asset & (18) (22) \\
\hline Organization learning & $\begin{array}{l}\text { Positive organization environment to facilitate knowledge } \\
\text { creation and sharing }\end{array}$ & $\begin{array}{l}(18)(19)(20)(23) \\
(24)(25)(27)\end{array}$ \\
\hline Process & Knowledge flow & (18) (20) (23) (28) \\
\hline Philosophical & $\begin{array}{l}\text { Higher understanding of knowledge toward development of } \\
\text { new way of thinking }\end{array}$ & (18) (20) \\
\hline Leadership & Management skill to support organization KM activities & $(19)(20)(22)(25)(27)$ \\
\hline Culture & & (20) (23) (25)(26) (28) \\
\hline People & Personal skills and competencies to handle KM Process & (23) $(24)(26)(27)$ \\
\hline
\end{tabular}

According to the mapping element above, the result shows that the major components are consists four elements, which are: Technology, organization learning, leadership, and culture. Therefore, these variables will be a based framework to collaborate with social media functionality and e-learning component framework.

This study also checks the major aspect for e-learning that focused from 2002 until 2015, which consist of in Table 2. 
Table 2. Components of e-learning

\begin{tabular}{ll}
\hline \multicolumn{1}{c}{ Components } & \multicolumn{1}{c}{ References } \\
\hline Social & $(29)(30)(31)(12)(32)(33)$ \\
Structure and Layout & $(29)(34)(35)(31)(33)(36)(37)$ \\
Communication & $(29)(31)$ \\
Process & $(37)(38)(33)$ \\
Evaluation & $(34)(38)(30)(33)(39)$ \\
Cooperative Learning Community & $(34)(30)(32)$ \\
Learning Resources & $(34)(30)(39)$ \\
Technology & $(34)(40)(12)(39)(36)$ \\
Pedagogy & $(34)(40)(12)(32)$ \\
Hypermediality & $(35)(31)$ \\
Ethical & $(34)$ \\
\hline
\end{tabular}

According to the finding, this research collaborate each element into a new conceptual model that integrate the significant component of knowledge management framework and social media framework, in Figure 4:

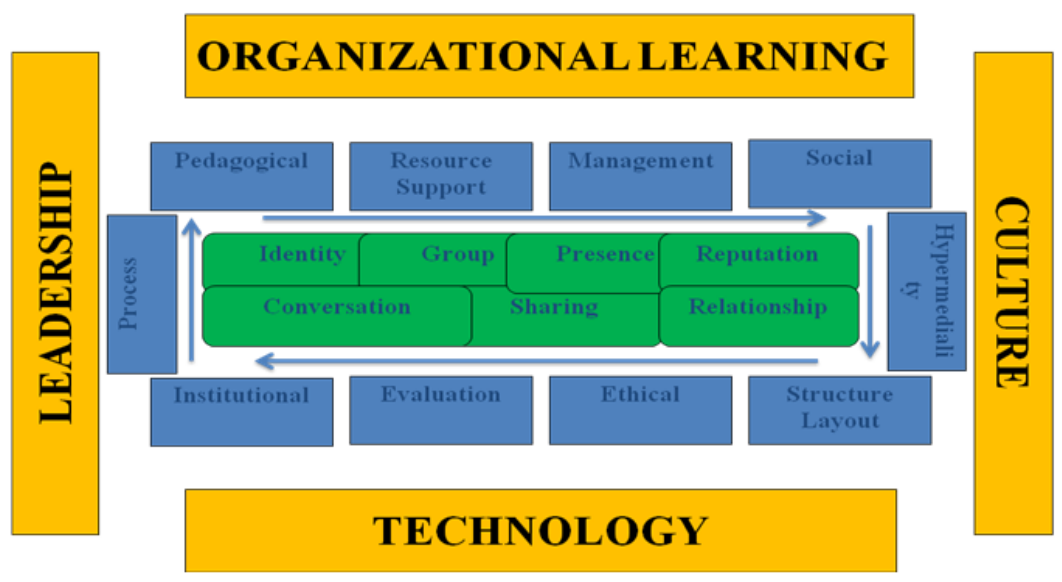

Figure 4. The Integration KM \& Social Learning Model

The proposed model collaborates social media functionality framework, e-learning element, and knowledge management components.

The main components to integrate knowledge management and social media consist of:

1. Technology is an important component of both e-learning and knowledge management for managing the distribution and use of knowledge, one of them is Learning Management System (LMS) as a tool to support learning process. Support is also required to manage collaboration room, user access, discussion forums, etc.

2. Pedagogy

The foundation of E-Learning is pedagogy, so learning process can be improved through guidance. The typical form or guidance come from the teacher or tutor to organize the learning process (41). Pedagogy concerns about content analysis, audience analysis, media analysis, etc.

3. Culture

Knowledge Management and E-Learning have a common goal to promote learning and competency development. Integration between knowledge management and E-Learning will accommodate continuous learning culture in organization (42).

4. Evaluation

Integration knowledge management and e-learning are important to do evaluation and assessment to be real situation (43).

5. Leadership

Management should demonstrate leadership in motivating and stimulating knowledge integration activities in the higher education. Leaders should shape a positive organization 
culture where the role of knowledge, $\mathrm{KM}$, innovation, and creative thinking is encouraged and valued(44).

6. Structure \& Layout

The structure and layout of the learning course enabling higher education to define which parts of the learning material are included in a particular learning course (44).

7. Organizational Learning

Knowledge Management is connected to many organizational perspectives; on the contrary, e-learning focuses on personal perspectives. Thus, one of the concerns of Knowledge Management integration can utilize learning resources of higher institution that it would strengthen the purpose of the organization(45).

8. Social

Collaboration is a significant process for E-Learning and Knowledge Management activities. It means communication and collaboration are the most important factors of successful education (46).

\section{Conclusion}

Learning identified as a fundamental to achieving sustainability intellectual of student (47). The rapid growth and current popularity of social media enhanced media learning to complement face to face session. Knowledge Management takes an organizational perspective on learning and E-Learning is the best way to help acquire the dynamic distributed, shared and collaborative knowledge through technological (48).

This study results a conceptual knowledge management model collaborate with social media functionality for higher education institution to define knowledge management framework components and significant social media components to integrate these two concepts. The components identified are based on study literature. Integration social media concept to enriched knowledge sharing process will give more flexibility which can upgrade the good learning experience and learning output.

\section{Limitation and Future Research}

The present research has some limitations that must be considered to get relevant improvements in the learning process. For future research, the model could be assessed by domain expert of knowledge management framework for validation. After that, this model could be tested in higher education for completing the list of relevant sustainability component to get the feedback from the higher education.

\section{References}

[1] Akbar SR, Setiawan E, Basuki A. Home Appliance Control with Publish Subscribe in Social Media. TELKOMNIKA (Telecommunication Computing Electronics and Control). 2015; 13(2): 678-685.

[2] Ruhwinaningsih L, Djatna T. A Sentiment Knowledge Discovery Model in Twitter's TV Content Using Stochastic Gradient Descent Algorithm. TELKOMNIKA (Telecommunication Computing Electronics and Control). 2016; 14(3).

[3] Ngai EWT, Tao SSC, Moon KKL. Social media research: Theories, constructs, and conceptual frameworks. Int J Inf Manage. 2015; 35(1): 33-44.

[4] Liu SH, Liao HL, Pratt JA. Impact of media richness and flow on e-learning technology acceptance. Comput Educ. 2009; 52(3): 599-607.

[5] Khan $\mathrm{BH}$. Managing e-learning: Design, delivery, implementation, and evaluation. Information Science Publishing. 2005.

[6] Tess PA. The Role of Social Media in Higher Education Classes ( Real and Virtual ) - A literature review. Comput Human Behav. 2013; 29(5): 60-68.

[7] Falahah, Rosmala D. Study of Social Networking Usage in Higher Education Environment. ProcediaSoc Behav Sci. 2012; 67(November 2011): 156-166.

[8] Kietzmann JH, Hermkens K, P McCarthy I. Social media? Get serious! Understanding the functional building blocks of social media. Bus Horiz. 2011; 54.

[9] Oktavia T, Warnars HLHS, Adi S, Meyliana, Prabowo H, Supangkat SH. Knowledge Management and Social Learning Integration: A Conceptual Model for Higher Education. Far East J Electron Commun. 2016; 16(4).

[10] Reilly P. Understanding and Teaching Generation Y. English Teach Forum. 2012.

Conceptual Model of Knowledge Management and Social Media to Support ... (Tanty Oktavia) 
[11] Rasiah RRV. Transformative Higher Education Teaching and Learning: Using Social Media in a Team-Based Learning Environment. Procedia-Soc Behav Sci. 2014; 123(2014): 369-379.

[12] Zheng Y, Yano Y. A framework of context-awareness support for peer recommendation in the elearning context. Br J Educ Technol. 2007; 38: 197-210.

[13] Woo Y, Reeves TC. Meaningful interaction in web-based learning: A social constructivist interpretation. Internet High Educ. 2007; 10(1): 15-25.

[14] V Rasiah RR. Transformative Higher Education Teaching and Learning: Using Social Media in a Team-based Learning Environment. Procedia-Soc Behav Sci. 2014; 123(2012): 369-379.

[15] Horton W. E-Learning by Design. 2nd edition. San Fransisco: John Wiley and Sons, Inc; 2012.

[16] Wild $\mathrm{RH}$, Griggs KA, Downing T. A framework for e-learning as a tool for knowledge management. Ind Manag Data Syst. 2002; 102(7): 371-380.

[17] Chu KW, Wang M, Yuen AHK. Implementing knowledge management in school environment: Teachers' perception. Knowl Manag E-Learning. 2011; 3(2): 139-152.

[18] Shin M. A framework for evaluating economics of knowledge management systems. Inf Manag. 2004; 42(1): 179-196.

[19] Cranfield DJ, Taylor J. Knowledge Management and Higher Education: A UK Case Study. Electron J Knowl Manag. 2008; 6(2): 85-100.

[20] Bures V, Griffin D, Hackett D, Kročitý P, Kubička E. Rethinking of Knowledge Management Introduction At Teaching Universities : the. Probl Educ 21st Century. 2011; 32.

[21] Hsia T, Lin L, Wu J, Tsai H. A Framework for Designing Nursing Knowledge Management Systems. Interdiscip J Information, Knowledge, Manag. 2006; 1.

[22] Chan EWL, Walker DHT, Mills A. Using a KM framework to evaluate an ERP system implementation. J Knowl Manag. 2009; 13(2): 93-109.

[23] Akramin Z, Drus M, Singh D, Mokhtar R. A Review: Knowledge Management Framework for Drug Rehabilitation Centre. Res J Appl Sci Eng Technol. 2013; 5(1): 292-295.

[24] Lin YC, Ha N. The Framework for KM Implementation in Product and Service Oriented SMEs: Evidence from Field Studies in Taiwan. Sustainability. 2015: 2980-3000.

[25] Smuts H, Merwe A Van Der, Loock M, Kotzé P. A Framework And Methodology For Knowledge. 2004.

[26] Bhusry M, Ranjan J. Implementing knowledge management in higher educational institutions in India: A conceptual framework. Int J Comput Appl. 2011; 29(1): 34-46.

[27] Ajuhary SA. Knowledge Management: From Strategy to Framework (A Case Study in Research Institute). 2015: 8-9.

[28] Pancholi DN, Pancholi DA. Designing a Conceptual Framework of Knowledge Management Process in Banks. IOSR J Bus Manag. 2014; 16(7): 114-126.

[29] Alias N, Zakariah Z, Ismail NZ, Aziz MNA. E-Learning Successful Elements for Higher Learning Institution in Malaysia. Procedia-Soc Behav Sci. 2012; 67(November 2011): 484-489.

[30] Amornsinlaphachai P. The Design of a Framework for Cooperative Learning through Web Utilizing Data Mining Technique to Group Learners. Procedia-Soc Behav Sci. 2015; 174: 27-33.

[31] Grigoraş G, Dănciulescu D, Sitnikov C. Assessment Criteria of E-learning Environments Quality. Procedia Econ Financ. 2014; 16(May): 40-46.

[32] Redmond $P$, Lock JV. A flexible framework for online collaborative learning. Internet High Educ. 2006; 9(4): 267-276.

[33] Boud D, Prosser M. Appraising New Technologies for Learning: A Framework for Development. EMI Educ Media Int. 2002; 39(3-4): 237-245.

[34] Ramakrisnan P, Yahya YB, Hasrol MNH, Aziz AA. Blended Learning: A Suitable Framework For ELearning In Higher Education. Procedia-Soc Behav Sci. 2012; 67: 513-526.

[35] Alsobhi AY, Khan N, Rahanu H. DAEL Framework: A New Adaptive E-learning Framework for Students with Dyslexia. Int Conf Comput Sci ICCS 2015 — Comput Sci Gates Nat. 2015; 51: 19471956.

[36] Abbas Z, Umer M, Odeh M, McClatchey R, Ali A, Ahmad F. A Semantic Grid-based E-Learning Framework (SELF) The Semantic Grid in E-learning. 2010.

[37] Songkram N. E-learning System in Virtual Learning Environment to Develop Creative Thinking for Learners in Higher Education. Procedia-Soc Behav Sci. 2015; 174: 674-679.

[38] Songkram N, Khlaisang J, Puthaseranee B, Likhitdamrongkiat M. E-learning System to Enhance Cognitive Skills for Learners in Higher Education. Procedia-Soc Behav Sci. 2015; 174: 667-673.

[39] Wan Z, Wang Y, Haggerty N. Why people benefit from e-learning differently: The effects of psychological processes on e-learning outcomes. Inf Manag. 2008; 45(8): 513-521.

[40] Salmon G. Flying not flapping: a strategic framework for e-learning and pedagogical innovation in higher education institutions. Alt-J, Res Learn Technol. 2005; 13(3): 201-218.

[41] Khademi M, Kabir H, Haghshenas M. E-learning as a Powerful Tool for Knowledge Management. In 5th International Conference on Distance Learning and Education. 2011: 40-44.

[42] Judrups J. Analysis of Knowledge Management and E-Learning Integration Models. Procedia Comput Sci. 2015; 43(Dalkir): 154-162.

TELKOMNIKA Vol. 15, No. 2, June $2017: 678-685$ 
[43] Elrehail HH, Trad MA, Algraibeh KM. Applying Knowledge Management Oriented Objectives into Distance E-Learning Process and Strategies. Management. 2013; 3(6): 316-322.

[44] Vasilyeva E, Pechenizkiy M, Puuronen S. Knowledge Management Challenges in Web-Based Adaptive e-Learning Systems. In I-Know '05. 2005.

[45] Owayid AM, Alrawi K, Shaalan K. Strategic change in knowledge management and e-learning: Enhancing workplace learning. Eur J Sci Res. 2013; 4(2): 47-53.

[46] Yordanova K. Integration of Knowledge management and E-learning - common features. In International Conference on Computer Systems and Technologies-CompSysTech 2007. 2007; 94: 196.

[47] Bos JJ, Brown RR, Farrelly MA. A design framework for creating social learning situations. Glob Environ Chang. 2013; 23(2): 398-412.

[48] Qwaider WQ. E-Learning system and Knowledge Management was the social nature of construction knowledge. Int J e-Learning Secur. 2014; 4(June): 350-353. 